\title{
SUBMERSÃO DE SEMENTES DE FEIJÃO DO GRUPO PRETO E DESENVOLVIMENTO INICIAL DE PLÂNTULAS
}

\author{
OGAWA, Nathalia Shizue ${ }^{1}$ \\ SENEME, Adriana Martinelli $i^{*}$ \\ MENDONÇA, Cristina Gonçalves de ${ }^{1}$ \\ FERRIANI, Aurea Portes ${ }^{1}$
}

\begin{abstract}
RESUMO: O processo de germinação depende de vários fatores destacando-se o percentual de umidade na semente. Durante o período de embebição, a falta de oxigênio pode levar a alteração da via respiratória aeróbica para anaeróbica e, no caso da via fermentativa, a capacidade de germinação será comprometida, reduzindo o vigor das plântulas o que compromete o desempenho da produção. Objetivou-se, com este trabalho, avaliar o efeito de diferentes períodos de submersão de sementes no desenvolvimento inicial de plântulas de feijão. Foram utilizadas duas cultivares de feijão do Grupo Preto, denominadas Soberano e FTS41. Foram determinados os teores de água inicial e final, após diferentes períodos de embebição $(0,2,4,6,8$ e 24 horas), índice de velocidade de emergência, altura de plântulas, emergência final e peso de matéria seca da parte aérea das plântulas. $O$ delineamento experimental foi inteiramente casualizado com 4 repetições por tratamento, avaliados posteriormente pelo teste $\mathrm{F}$ e análise de regressão. Os resultados demonstraram que sementes da cultivar FTS 41 sofreram embebição mais rapidamente que as da cultivar Soberano; a partir de 4 horas de embebição houve prejuízo ao desempenho das plântulas da cultivar Soberano, no entanto, para diferenciação dos lotes de feijão o período indicado de submersão das sementes deve ser de 8 horas.
\end{abstract}

Palavras-chave: Hipoxia. Teor de água. Armazenamento. Vigor.

SUMMARY: The germination process depends on several factors, standing out the moisture percentage in the seed. During a period of soaking, the lack of oxygen can change from the aerobic respiratory pathway to the anaerobic. If the process follows to the fermentation route, the germination capacity will be compromised. This study aimed to evaluate the effect on the initial development of bean seedlings in different water submersion periods. Two cultivars were used, Soberano and FTS41. Both belong to the Black group, and the following parameters were evaluated: initial seed moisture content, moisture content after different soaking periods ( $0,2,4,6,8$ and 24 hours), emergence speed index (ESI), seedling height, final emergence and dry matter weight of the aerial part of seedlings (in the greenhouse). The experimental design was completely randomized with four replicates per treatment, later evaluated by F test and regression analysis. The results showed that seeds of the cultivar FTS 41 suffered soaking faster than the cultivar Soberano; from 4 hours of soaking it hindered the performance of seedlings of the cultivar Soberano, however, for differentiation of bean plots the indicated period of submersion of the seed shall be 8 hours.

Keywords: Hypoxia. Moisture content. Storage. Vigour.

\section{INTRODUÇÃO}

O Brasil é um dos maiores produtores mundiais de feijão e o maior consumidor per capita. Cultivado por pequenos e grandes produtores e em diversificados sistemas de produção, o cultivo do feijoeiro apresenta uma baixa produtividade, em média de $946 \mathrm{~kg} \mathrm{ha}^{-1}$. A falta de utilização de sementes de boa qualidade é uma das principais causas da baixa produtividade.

\footnotetext{
${ }^{1}$ Departamento de Fitotecnia e Fitossanitarimo, Setor de Ciências Agrárias, Universidade Federal do Paraná, Rua dos Funcionários 1540, Bairro Juvevê, Curitiba, PR, Caixa Postal 19061, CEP 80035-050

* autora para correspondência: adriana.seneme @ hotmail.com
} 
Dentro do processo de produção, é fundamental a obtenção de sementes de alta qualidade pois, a germinação e a emergência das plântulas são reflexos da qualidade fisiológica (BRAGA et al., 1999). A qualidade fisiológica de sementes pode ser avaliada por meio dos parâmetros viabilidade e vigor (BERTOLIN, 2010).

Dentre os fatores externos que influenciam na qualidade das sementes, o que mais influencia no processo germinativo é a hidratação da semente, pois a água constitui a matriz onde ocorre a maioria dos processos bioquímicos e fisiológicos que resultam na protrusão da raiz primária (MORAES et al., 2005). Por ser um fator limitante, a disponibilidade de água para as sementes é diretamente relacionada com a germinação e a emergência.

O cultivo do feijão não tolera excesso contínuo de água no solo, causado principalmente por chuva em excesso, aliada a alguns tipos de solo que retém a água por mais tempo, retardando a germinação. Segundo Dantas et al. (2000), o excesso de água diminui a disponibilidade de oxigênio para o embrião, reduzindo ou atrasando a germinação em várias espécies. Assim, a capacidade de germinação fica comprometida, pois o período de embebição induz uma alteração da via respiratória aeróbia para a fermentativa ou anaeróbia (NEUMANN et al., 1999).

Outra consequência da submersão das sementes em água é a injúria por rápida embebição, que consiste na rápida entrada de água na semente devido à diferença de potencial hídrico entre a semente e o meio na qual ela está inserida. Segundo Richard et al. (1991), isto refletirá em menor vigor, pois a semente que estará danificada, terá menor quantidade de energia disponível para o processo germinativo. Para Dantas et al. (2000), o contato com quantidade excessiva de água leva à ruptura de membranas celulares resultando na lixiviação de eletrólitos, açúcares e aminoácidos. Outro fator desfavorável à germinação e vigor das sementes poderia ser a excreção de substâncias tóxicas às plantas no ambiente de alagamento.

No processo de embebição, as sementes adquirem a capacidade de regeneração de suas membranas reparando os danos químicos, físicos e biológicos que possam tê-la afetado durante alguma fase da produção, influenciando diretamente a quantidade de lixiviados liberados para o meio externo, ou seja, quanto mais rápida e bem sucedida for a regeneração das membranas quando submetidas ao processo de embebição, menor será a perda de lixiviados da semente para o meio externo, mantendo assim um maior vigor das sementes (Vieira e Krzyzanowski, 1999).

Algumas espécies podem suportar períodos de alagamento temporários ou mesmo prolongados. Há indícios que a perda de vigor, verificada após imersão em água controlada, pode ser utilizado para avaliação lotes, pois as sementes vigorosas seriam mais resistentes à condição desfavorável de submersão (CUSTÓDIO et al., 2009), identificando lotes que tenham a capacidade de suportar injúrias pela rápida embebição.

Em regiões úmidas e quentes, fatores bióticos e abióticos influenciam na perda de viabilidade e do vigor das sementes. Entre esses, o excesso de chuva, logo após a semeadura, pode ser um fator limitante à produção, por causar deterioração das sementes levando à menor emergência das plântulas em campo (CUSTÓDIO et al., 2002).

Este trabalho buscou avaliar o efeito dos períodos de submersão das sementes armazenadas na emergência e no desenvolvimento inicial de plântulas de feijão das cultivares Soberano e FTS41.

\section{MATERIAL E MÉTODO}

O trabalho foi conduzido no Laboratório de Análise e Tecnologia de Sementes e em casa de vegetação, ambos no Setor de Ciências Agrárias da Universidade Federal do Paraná, em Curitiba, nos meses de agosto e setembro de 2015. 
Foram utilizadas sementes de feijão (Phaseolus vulgaris L.) do grupo Preto, cultivares Soberano e FTS41, armazenadas há 365 dias, em ambiente de laboratório (sem controle de umidade relativa do ar e temperatura). As embalagens utilizadas para armazenagem foram garrafas PET transparentes, com tampa, com capacidade de 2 litros (CUNHA, 2013). Anteriormente à armazenagem, as sementes foram avaliadas quanto ao teor de água em estufa de $105^{\circ} \mathrm{C} / 24 \mathrm{~h}$ (BRASIL, 2009), determinou-se o peso de 100 sementes e foi realizado o teste de germinação (BRASIL, 2009).

Ambas cultivares possuem crescimento do tipo indeterminado, ciclo de 90 a 95 dias, cor das flores roxa e cor da vagem creme. As regiões recomendadas para o cultivo são Sul e Sudeste do Brasil, com densidade de semeadura de 200.000 plantas/ha. A cultivar FTS Soberano é ideal para colheita mecanizada pelo seu porte alto e ereto. Seu sistema radicular é agressivo e profundo, com tolerância aos fungos do solo e também as principais raças de antracnose. Já a cultivar FTS 41 apresenta um excelente potencial produtivo com notável desenvolvimento vegetativo, com guias médias e longas. Sua arquitetura é semi ereta, com porte alto, apropriado para colheita mecanizada. Seu sistema radicular é agressivo, com tolerância aos fungos causadores da murcha de Fusarium e as principais raças de antracnose. Em lavouras tecnicamente produzidas e em condições normais de clima e solo, a produtividade da cultivar Soberano ultrapassa de $3.000 \mathrm{~kg} / \mathrm{ha}$ e da FTS 41 pode atingir $4.000 \mathrm{~kg} / \mathrm{ha}$.

As sementes foram submersas em $100 \mathrm{ml}$ de água, em copos plásticos de $250 \mathrm{ml}$, utilizando-se quatro repetições por tratamento. As sementes permaneceram submersas pelos períodos de $0,2,4,6,8$ e 24 horas em câmara tipo BOD com temperatura constante de $25^{\circ} \mathrm{C}$. Após cada período de embebição, parte das sementes foi semeada em vasos em casa de vegetação (seis sementes/vaso à aproximadamente três $\mathrm{cm}$ de profundidade) e outra parte foi submetida ao teste para determinação do teor de água a $105^{\circ} \mathrm{C} / 24$ horas (BRASIL, 2009), gerando curvas de embebição durante as 24 horas de submersão.

Avaliou-se em casa de vegetação o índice de velocidade de emergência (contagem diária a partir da emergência da primeira plântula)(IVE)(MAGUIRE, 1962), porcentagem final de emergência (EP), altura de plântulas (AP) e peso de matéria seca (PMS) da parte aérea por planta (NAKAGAWA, 1994). Entre a semeadura (11 de setembro de 2015) e o final do experimento (24 de setembro de 2015), as temperaturas variaram entre $7^{\circ} \mathrm{C}$ e $33^{\circ} \mathrm{C}$.

Os resultados foram analisados em esquema fatorial $2 \times 6$ (cultivares $\times$ períodos) em delineamento inteiramente casualizado com quatro repetições e feito teste F. Foram ajustados modelos de regressão linear (representado pela equação $\mathrm{y}=\mathrm{a}+\mathrm{bx}+\mathrm{cx}^{2}$ ) para estabelecer as tendências entre os períodos de embebição e as variáveis estudadas e o critério de seleção dos modelos foi a magnitude dos coeficientes de determinação.

\section{RESULTADOS E DISCUSSÃO}

O teor de água médio (TA) das sementes no momento do recebimento foi de $12,1 \%$ para a cultivar Soberano, e 12,3\% para a FTS41. As sementes das cultivares Soberano e FTS41 apresentaram peso médio de 100 sementes 24,82 e 21,15 gramas, respectivamente. No teste de germinação, a cultivar Soberano apresentou valor médio de $83 \%$ e a FTS41 de $65 \%$.

Os resultados da análise de variância estão apresentados na Tabela 2. Não houve efeito significativo para cultivar para as variáveis altura de plântulas (AP) e peso de matéria seca (PMS). 
Tabela 2. Análise de variância para teor de água (\%) de sementes, índice de velocidade de emergência (\%), altura de plântulas $(\mathrm{cm})$ e peso de matéria seca (g) das cultivares de feijão FTS41 e Soberano.

\begin{tabular}{|c|c|c|c|c|c|c|}
\hline \multirow{2}{*}{ Fonte de variação } & \multirow{2}{*}{ G.L. } & \multicolumn{5}{|c|}{ VALORES DE F } \\
\hline & & TA & EP & IVE & AP & PMS \\
\hline Período (P) & 5 & $2122,44 * *$ & $0,35 * *$ & $3.38 * *$ & $6.29 * *$ & 0,0051 \\
\hline Cultivar (C) & 1 & $87,75^{* *}$ & $1,60 * *$ & $28.20 * *$ & $0.74^{\mathrm{ns}}$ & 0,0017 \\
\hline Interação (PxC) & 5 & $11,67 * *$ & $0,17 * *$ & $1.19 *$ & $2.99 * *$ & 0,0003 \\
\hline Período X Soberano & 5 & $1029,13 * *$ & $0,41 * *$ & $3.14 * *$ & $7.94 * *$ & 0,0030 \\
\hline Período X FTS41 & 5 & $1104,98 * *$ & $0,11^{*}$ & $1.43 * *$ & $1.34 *$ & 0,0023 \\
\hline Erro & 36 & 1,32 & 0,045 & 0,38 & 0,51 & 0,0010 \\
\hline Média Geral & & 43,53 & 82,25 & 3,3 & 6,71 & 0,1884 \\
\hline C.V. $(\%)$ & & 2,64 & 16,97 & 18,7 & 10,61 & 17,32 \\
\hline
\end{tabular}

**significativo a 1\%; *significativo a 5\%; ns: não significativo (de acordo com o teste F); C.V.: Coeficiente de Variação.

Os resultados referentes à absorção de água durante os períodos de embebição estão apresentados na Figura 1.

Figura 1 - Teor de água (\%) de sementes de feijão das cultivares Soberano e FTS41 em seis períodos de embebição ( $0,2,4,6,8$ e 24 horas).

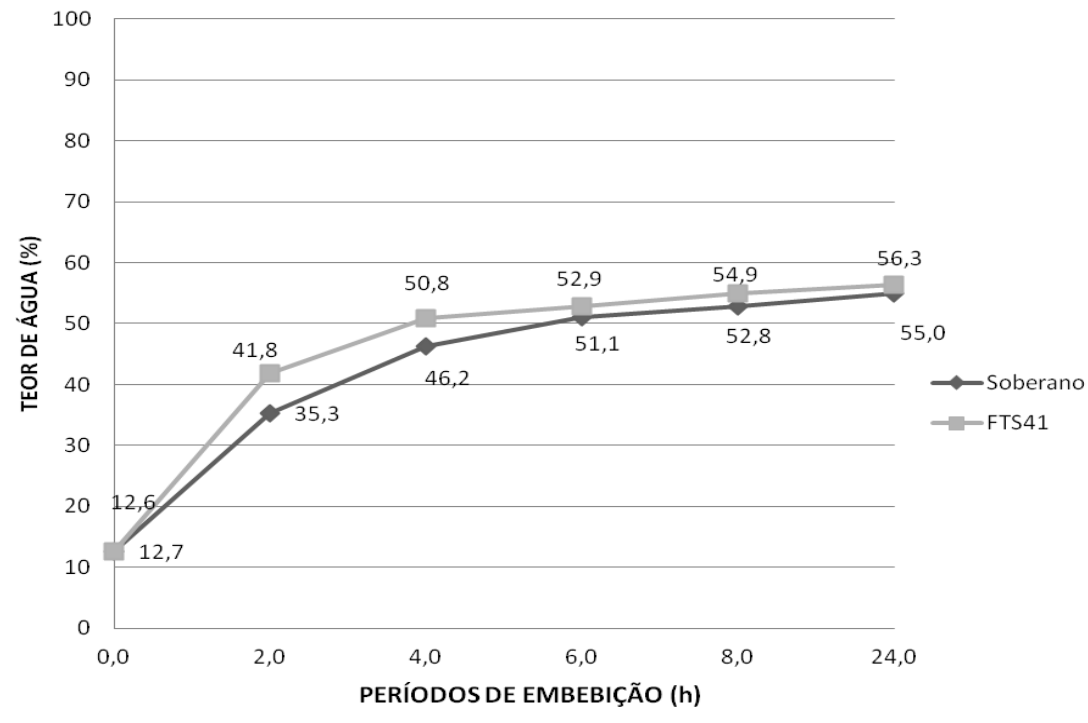

Fonte: Elaborado pelos autores (2015).

Sementes de ambas cultivares, Soberano e FTS41, apresentaram curvas de embebição semelhantes, com tendência ascendente, ou seja, o teor de água das sementes sofreu acréscimos à medida que se prolongaram os períodos de embebição (Figura 2A).

Custódio et al. (2009) avaliaram o vigor de sementes de feijão em alagamento nos períodos 0, 4, 8, 12 e 16 horas. Os autores observaram que a média dos teores de água (\%) das cultivares analisadas no período de $4 \mathrm{~h}$ de embebição foi de 42,5\% (30,9 53,4\%); em 8 horas de embebição foi 52,4\% (48,7 55,2\%); em 16 horas foi de 56,5\% (período máximo analisado neste trabalho). 
Em outro trabalho deste mesmo autor (CUSTÓDIO et al., 2002), as sementes submetidas a 24 h de alagamento apresentaram média de teor de água 58,2\%, sendo que nos períodos de 32, 40 e 48 horas, este percentual manteve-se basicamente constante $(57,4 \%, 57,9 \%$ e 58,6\%, respectivamente). Foi observado decréscimo na germinação e no vigor com o aumento da submersão das sementes em água, sendo $4 \mathrm{~h}$ o suficiente para o estabelecimento da cultura em lotes menos vigorosos, e 8 horas até para os lotes mais vigorosos, causando danos irreversíveis ao estabelecimento da cultura do feijoeiro.

Em trabalho feito por Vieira (2012), a determinação do teor de umidade das sementes de feijão foi conduzida antes e após cada período de submersão, e observou-se que a embebição foi rápida no início da submersão até o período de quatro horas, a partir do qual a embebição foi mais lenta, iniciando-se a fase estacionária da embebição. Os resultados observados neste trabalho (Figura 1) mostraram que a embebição das sementes do cultivar FST41 ocorreu mais rapidamente. Até o período de 4 h houve incremento de 38,2\% (de 12,6\% para 50,8\%) no teor de água das sementes do cultivar FTS 41 enquanto para o cultivar Soberano, no mesmo período, houve elevação do teor de água em 33,5\% (de 12,7\% para $46,2 \%)$.

Quanto mais seca a semente, maiores podem ser os danos causados pela rápida embebição e maiores os conteúdos de eletrólitos lixiviados (VIEIRA, 2012). Neste estudo, os valores de teor de água das sementes apresentaram-se muito próximos, no ato do recebimento, no momento da embebição e no período de 24 horas.

Segundo Nakagawa (1994), pelo IVE (índice de velocidade de emergência), quanto maior o valor obtido subentende-se maior velocidade de germinação e vigor, pois o índice calculado estima o número médio de plântulas normais por dia. Os resultados de emergência (EP) e índice de velocidade de emergência (IVE) das cultivares Soberano e FTS 41 (Figuras 2B e 2C) foram similares aos obtidos por Custódio et al. (2009), no qual verificou-se que a germinação e o vigor foram negativamente afetados pela submersão das sementes em água, e que houve uma redução da porcentagem de germinação de sementes de feijão quando foram_expostas a quatro ou mais horas de submersão, podendo assim ser suficiente para avaliar o vigor dos lotes. Os resultados obtidos para FTS 41 são semelhantes aos de Costa et al. (2015) para o cultivar BR Campeiro que, embora tenha sido o melhor entre os cultivares testados, apresentou redução na germinação (99\% para 73\%) a partir de 8 horas de embebição._Ribeiro et al. (2014) observaram diferença nos cinco períodos $(2,4,8,12$, e 24 h) para as 8 em 10 cultivares de feijão analisadas, sendo que as duas cultivares não apresentaram diferença na condutividade elétrica (CE) ao ficarem submersas na solução em 2 ou 4 horas, e apenas foi possível verificar alteração nos valores a partir de 8 horas.

Já para a cultivar Soberano a partir de 2 horas já houve prejuízo à emergência das plântulas (redução de 100 para 88\%) (Figura 2B). Costa et al. (2015) observaram que sementes de feijão tiveram sua germinação reduzida a partir de 2 horas de embebição, para o cultivar IPR Tiziu (de 91\% para 63\%) e para a cultivar IPR 139 (de 90\% para 58\%).

Para a cultivar Soberano, todas as variáveis estudadas, com exceção da altura, podem ser representadas por um polinômio de $2^{\circ}$ grau (Figura 2) com coeficiente de determinação $\left(\mathrm{R}^{2}\right)$ de 0,634 a 0,922. A análise da variável altura não apresentou uma equação significativa para representar a relação.

A causa da redução na germinação pode estar relacionada com a hipóxia, condição de deficiência de oxigênio a qual as sementes foram submetidas, uma vez que em um ambiente anaeróbio, o metabolismo muda de respiração para fermentação, que apresentam as vias do ácido láctico e alcoólica. A primeira vai gerar ácido láctico que irá diminuir o $\mathrm{pH}$ da célula, causando assim um mau funcionamento de várias enzimas, desde produção de energia até a desintoxicação de células, o que pode ser responsável pelo colapso das células. Na via de álcool, os produtos finais são muito tóxicos e, dependendo da quantidade 
produzida, a proteína desnaturada também conduzirá a um colapso das células (Custódio et al., 2002; Custódio et al, 2009).

Os resultados também estão de acordo com Dantas et al. (2000), que observaram que em milho a germinação de sementes sofreu maior inibição quanto maior foi o período de alagamento. Além disso, estes mesmos autores concluíram que a submersão em água é uma alternativa viável para a avaliação de vigor de forma fácil, simples e de baixo custo. Porém, no teste de embebição em água para sementes de soja feito por Rego et al. (2014), não foi observada significância entre as variáveis nos períodos de embebição (3, 6, 9 e 12 horas), para as temperaturas $25^{\circ} \mathrm{C}$ e $30^{\circ} \mathrm{C}$. Sendo assim, estas variáveis testadas não foram eficientes para a determinação de vigor de sementes.

Figura 02. Teor de água das sementes (A), emergência de plântulas (B), índice de velocidade de emergência (C), altura de plantas (D) e peso de matéria seca (E) das cultivares FTS41 e Soberano em seis períodos de embebição.

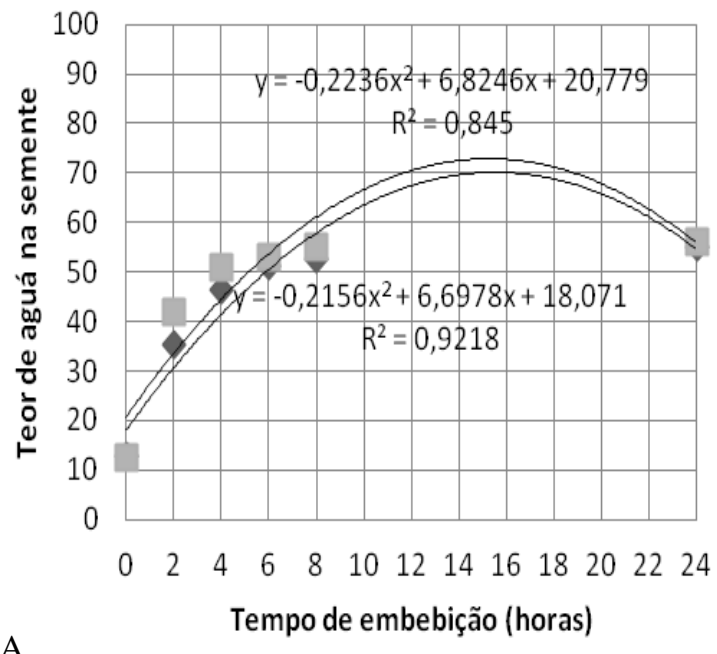

A

- Soberano FTS41

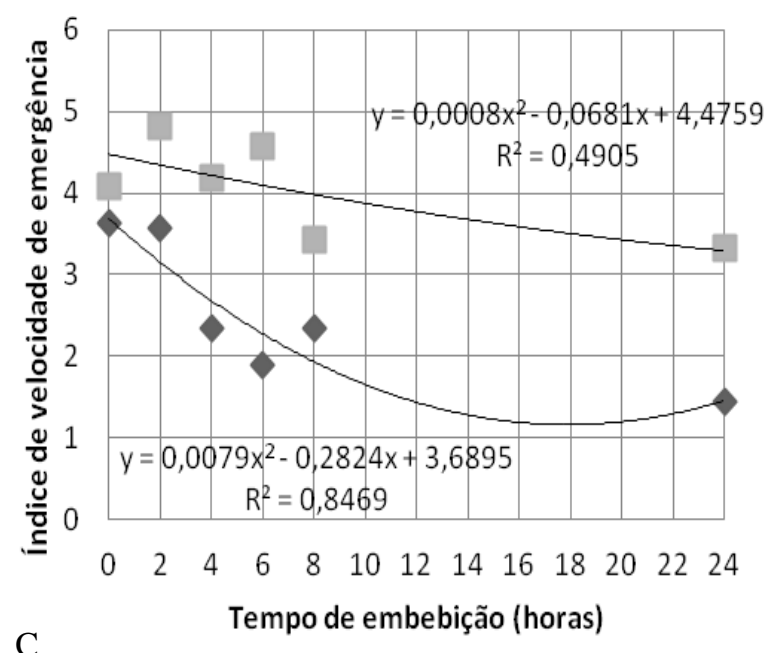

- Soberano $\mathrm{FTS} 41$
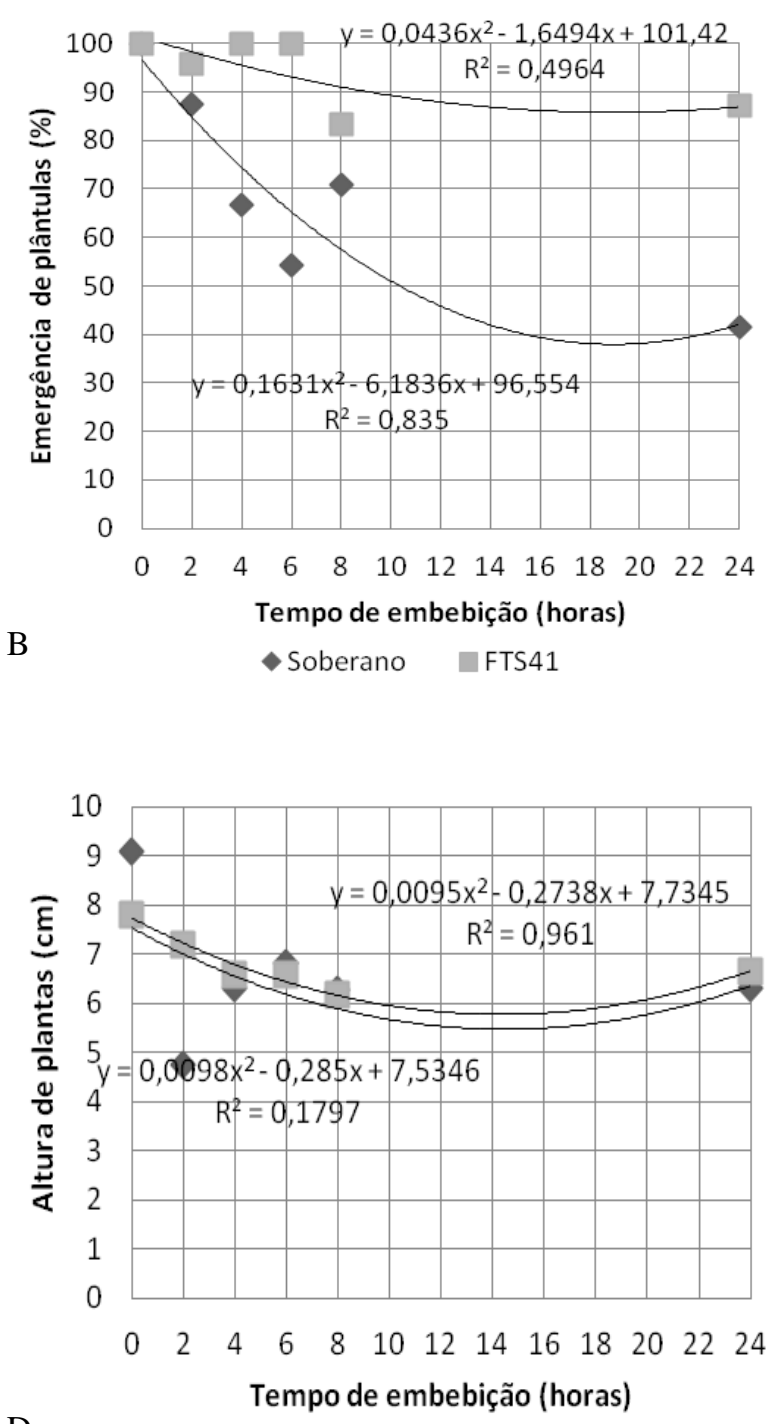

\Soberano IFTS41 


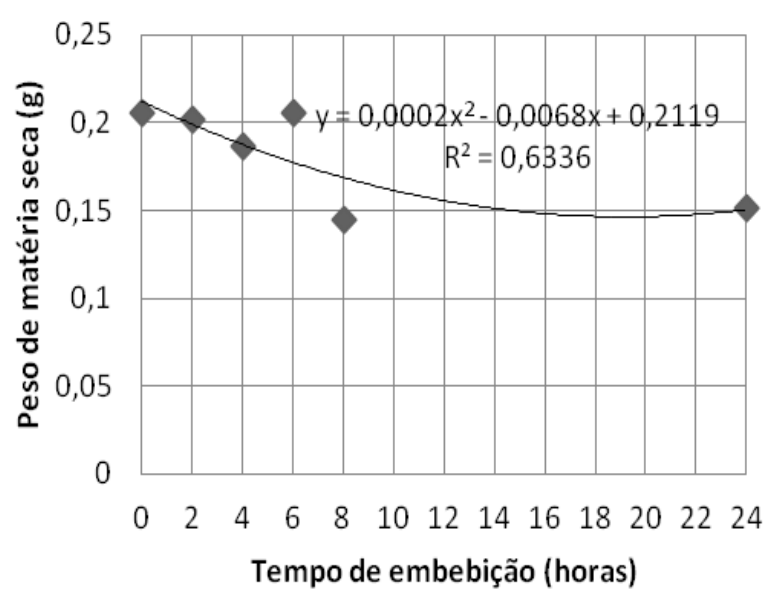

$\mathrm{E}$

$\checkmark$ Soberano

A partir de 2 horas houve redução na altura de plântulas das cultivares Soberano e a FTS41 (Figura 2D). Custódio et al. (2002) observaram que os períodos de alagamento diferiram significativamente, porém ambos os lotes de feijão comportaram-se de modo semelhante, apresentando uma crescente inibição ao desenvolvimento do hipocótilo com o aumento do período de submersão. Em trabalho de Vieira (2012), o comprimento da parte aérea originadas das sementes de feijão que passaram por submersão em água apresentou diferenças entre cultivares, dentro de cada período, porém apenas nos períodos de 1 a 4 horas. Neste mesmo trabalho, o autor concluiu que a perda de germinação e vigor é diretamente proporcional ao tempo de imersão, ao qual as cultivares foram submetidos, sendo o período de uma hora de submersão suficiente para que as diferenças de germinação entre as cultivares começassem a aparecer.

Para matéria seca de plântulas não houve interação significativa entre períodos e o cultivar FTS41. Para o cultivar Soberano a embebição das sementes ocasionou redução no peso de matéria seca das plântulas. Os resultados encontrados estão de acordo com o trabalho feito por Custódio et al. (2002), que observaram que as médias dos pesos secos da parte aérea diferiram significativamente nos diferentes períodos de embebição, apresentando redução em todos os períodos. Também Vieira (2012) observaram que houve diferenças na massa seca da parte aérea entre as cultivares de feijão nos períodos $0,1,2$ e 4 horas de submersão. Em períodos superiores, a submersão deprimiu acentuadamente o crescimento da parte aérea e da plântula toda de tal forma que as cultivares se igualaram.

\section{CONCLUSÃO}

Sementes da cultivar FTS 41 embeberam mais rapidamente que as da cultivar Soberano; a partir de 4 horas de embebição há prejuízo ao desempenho das plântulas da cultivar Soberano, no entanto, para diferenciação dos lotes de feijão o período indicado de submersão das sementes deve ser 8 horas.

\section{REFERÊNCIAS}

BERTOLIN, D. C. Teste de alagamento, deterioração controlada e envelhecimento acelerado para avaliação do vigor de sementes de feijão. 2010. $112 \mathrm{f}$. Tese (doutorado) - Universidade Estadual Paulista, Faculdade de Engenharia de Ilha Solteira, 2010. 
BRAGA, L.F.et al.Efeito da disponibilidade hídrica do substrato na qualidade fisiológica de sementes de feijão. Revista Brasileira de Sementes, Brasília, v.21, n.2, p.95-102, 1999.

BRASIL. Ministério da Agricultura, Pecuária e Abastecimento. Regras para análise de sementes. Brasília, DF: MAPA/ACS, Secretaria de Defesa Agropecuária, 2009. 399p.

COSTA, C. J.; SILVA, M.G.; FRANCO, D.F. Germinação de sementes de feijão submetidas à submersão em água. Boletim de Pesquisa e Desenvolvimento, 226. Pelotas: Embrapa Clima Temperado, 2015. 17p.

CUNHA, D.A. Potencial fisiológico de sementes de gergelim preto (Sesamum indicum l.) em resposta a diferentes condições de acondicionamento [trabalho de conclusão de curso]. Anápolis - GO:

Universidade Estadual de Goiás, Curso de Engenharia Agrícola; 2013.

CUSTÓDIO, C.C.et al. Efeito da submersão em água de sementes de feijão na germinação e no vigor.

Revista Brasileira de Sementes, vol. 24, nº 2, p.49-54, 2002

CUSTÓDIO, C. C.et al.. Water submersion of bean seeds in the vigour evaluation. Revista Brasileira de Ciências Agrárias (Agrária) Brazilian Journal of Agricultural Sciences, v.4, n.3, 2009.

DANTAS, B. F. et al. Efeito da duração e da temperatura de alagamento na germinação e no vigor de sementes de milho. Revista Brasileira de Sementes, v. 22, n. 1, p. 88-96, 2000.

MAGUIRE, J.D. Speed of germination-aid in selection and evaluation for seedlig emergence and vigor.

Crop Science, Madison, v.2, n.1, p.176-177,1962.

MORAES, G. A. F.; MENEZES, N. L.; PASQUALLI, L. L. Comportamento de sementes de feijão sob diferentes potenciais osmóticos. Ciência Rural, Santa Maria , v. 35, n. 4, p. 776-780, 2005.

NAKAGAWA, J. Testes de vigor baseados na avaliação das plântulas. In: VIEIRA, R. D., CARVALHO, N. M. (Ed.) Testes de vigor em sementes. Jaboticabal: FUNEP, 1994.

NEUMANN, G.et al.. Thiamine (vitamin B1) deficiency in germinating seeds of Phaseolus vulgaris L. exposed to soaking injury. Journal of Plant Nutrition and Soil Science, Weinheim, v.162, n.3, p.295-300, 1999.

REGO C.H.Q.et al. Teste de embebição em água para sementes de soja. Journal of Agronomic Sciences, Umuarama, v.3, n.2, p.178-185, 2014.

RIBEIRO, A. A.et al. Diferentes temperaturas e tempos de embebição de sementes de feijoeiro para realização do teste de condutividade elétrica. Nucleus, Ituverava, v. 11, n. 2, p. 425-432, 2014. ISSN 1982-2278.

RICHARD, B.et al. Anaerobic stress induces the transcription and translation of sucrose synthase in rice. Plant Physiology, Rockville, v.95, n.3, p.669- 674, 1991.

VIEIRA G. H. M. Germinação e vigor de sementes de feijão comum em condição de submersão em água. 2012. 36f. Dissertação (Mestrado em Agronomia)- Universidade do Oeste Paulista - Unoeste, Presidente Prudente, SP, 2012.

VIEIRA, R.D.; KRZYZANOWSKI, F.C. Teste de condutividade elétrica. In: VIEIRA, R.D.; KRZYZANOWSKI, F.C.; FRANÇA NETO, J.B. (Ed.). Vigor de sementes: conceitos e testes. Londrina, PR: ABRATES, 1999. cap.4, p.1-26. 